\title{
Quality Control and Complication Screening Programme of Chinese Medicinal Drugs at the First German Hospital of Traditional Chinese Medicine - A Retrospective Analysis
}

\author{
Dieter Melchart $^{\mathrm{a}, \mathrm{b}}$ Stefan Hager ${ }^{\mathrm{c}}$ Jingzhang Dai ${ }^{\mathrm{c}, \mathrm{d}}$ Wolfgang Weidenhammer ${ }^{\mathrm{a}}$ \\ ${ }^{a}$ Competence Centre for Complementary Medicine and Naturopathy (CoCoNat), Klinikum rechts der Isar, Technische Universität \\ München, Munich, Germany \\ ${ }^{b}$ Institute for Complementary and Integrative Medicine, University Hospital Zurich and University of Zurich, Zurich, Switzerland; \\ ${ }^{\mathrm{c}}$ TCM hospital Bad Kötzting, Bad Kötzting, Germany \\ ${ }^{\mathrm{d}}$ Beijing University of Chinese Medicine, Beijing, China
}

\section{Keywords}

Traditional Chinese Medicine $\cdot$ Hepatotoxicity · Herb-induced liver injury . Chinese medicinal drugs - Elevated liver enzyme . Quality control · Screening programme

\section{Summary}

Background: The use of drugs derived from plants is a cornerstone of Traditional Chinese Medicine (TCM). Yet, too little is known about risk and safety of Chinese medicinal drugs (CMD). Therefore, the TCM hospital Bad Kötzting has developed a quality control and complication screening programme in order to ensure a safe administration of TCM drugs to their patients. Methods: All Chinese medicinal drugs delivered to the hospital between September 1, 2012 and December 31, 2013 entered the quality control program and were screened for microbial contamination, aflatoxin, pesticides and heavy metals. A routinely applied complication screening programme monitored liver enzymes in all patients. Case causality assessment by CIOMS scale and identification of admitted herbs were conducted. Additionally, side effects of patients were identified by a routinely performed web-based documentation system. Results: In 5 of 23 investigated samples $(21.7 \%)$ the initial testing showed microbial contamination (2), pesticide (2) and heavy metals (1). The drugs were tested for authenticity and adulterations, respectively. All 994 patients (mean age 52.6 years; $72.6 \%$ female) admitted were available for analysis. $448(45.1 \%)$ of all patients reported having perceived at least one side effect of treatment. They experienced mainly gastrointestinal symptoms $(13.6 \%)$, neurovegetative symptoms $(10.8 \%)$, temporary deteriorations of pain $(8.8 \%)$, diarrhoea $(5.9 \%)$, nausea (1.6\%) and vomiting $(0.5 \%)$. Further, 6 patients with a more than 2-fold elevation (compared to maximum normal value or elevated admission values) of ALT were found in the systematic laboratory control with a non-conclusive causality assessment for TCM-drugs. Conclusion: Approximate incidence rates and analysed drugs associated with liver damage revealed a low rate of liver injury. Patients should be informed of the gastrointestinal symptoms caused by and potential hepatotoxicity of TCM herbs.

\section{Schlüsselwörter}

Traditionelle Chinesische Medizin · Hepatotoxizität . Leberschäden . Chinesische Arzneimittel . Erhöhte Leberwerte . Qualitätskontrolle · Unerwünschte Nebenwirkungen

\section{Zusammenfassung}

Hintergrund: Die Verwendung von Arzneipflanzen ist ein Eckpfeiler der traditionellen chinesischen Medizin (TCM). Dennoch existiert immer noch zu wenig Wissen über deren Risiken und Sicherheit. Aus diesem Grunde hat die erste deutsche Klinik für TCM Bad Kötzting zum Schutz der Patienten ein Programm zur Qualitätssicherung der chinesischen Arzneidrogen und deren systematischen Erfassung entwickelt und eingeführt. Methodik: Alle in der Zeit vom 1.9.2012 bis 31.12.2013 in die Klinik angelieferten TCM-Arzneidrogen wurden in das Qualitätssicherungsprogramm einbezogen und auf mikrobielle Kontamination, Aflatoxine, Pestizide und Schwermetalle untersucht. Durch eine systematische Laborerfassung von Leberenzymen aller aufgenommenen Klinikpatienten wurden mögliche Leberwertveränderungen dokumentiert, alle verordneten Arzneimittel erfasst und bei Auftreten von möglichen Leberschäden eine Kausalitätsbewertung anhand der leberspezifischen CIOMS-Skala durchgeführt. Schließlich wurden subjektiv unerwünschte Therapiewirkungen über ein webbasiertes Gesundheitsdossier dokumentiert. Ergebnisse: In 5 von 23 Arzneimittel-Chargen (21,7\%) wurde eine mikrobielle Belastung $(n=2)$, Pestizide $(n=2)$ und Schwermetalle $(n=1)$ gefunden. Die Drogen wurden auf Identität und Reinheit untersucht. Alle im Untersuchungszeitraum in die Klinik aufgenommenen Patienten ( $n=994)$ mit einem Durchschnittsalter von 52,6 Jahren und einem Frauenanteil von $72,6 \%$ wurden in die Analyse eingeschlossen. 448 Patienten $(45,1 \%)$ klagten über mindestens ein unerwünschtes Ereignis, wobei $13,6 \%$ über gastrointestinale $\mathrm{Be}$ schwerden, $10,8 \%$ über neurovegetative Störungen, 8,8\% über vorübergehende Schmerz-Verschlimmerungen, 5,9\% über Durchfälle, 1,6\% über Übelkeit und 0,5\% über Erbrechen klagten. In den systematischen Laborkontrollen fanden sich 6 Patienten mit mindestens 2-fach erhöhten GPT-Leberenzymwerten ohne überzeugenden Kausalitätshinweis auf bestimmte TCM-Drogen. Schlussfolgerung: Gelegentliche Erhöhungen von Leberenzymwerten als Hinweis auf potentielle Leberschäden durch TCM-Arzneimittel können auftreten. Die Patienten sollten auf die Möglichkeit des Auftretens von gastrointestinalen Beschwerden und von Leberschäden hingewiesen werden.

\section{KARGER}

(c) 2016 S. Karger GmbH, Freiburg

$1661-4119 / 16 / 0237-0021 \$ 39.50 / 0$ 


\section{Background}

Between 1991 and 2011, German social health insurance companies have agreed to reimburse the inpatient treatment at TCM hospital Bad Kötzting if patient characteristics, treatments, outcomes and side effects were continuously evaluated. The investigations were performed in collaboration with the Centre of Complementary Medicine and Naturopathy (CoCoNat), Technical University of Munich, and Centre of Pharma Research, University of Munich. The most important therapeutic part of TCM is Chinese medicinal drugs (CMD). They are widely used in Asian communities throughout the world for a broad array of conditions [1]. CMD compounds are of herbal and non-herbal nature and commonly prescribed concurrently. The medications are usually administrated as decoctions (tang). A few of them are served as syrups (tang jiang) and medicinal wines (Jiu). Although Chinese drug remedies appear to be relatively safe they are not free of risks, and a number of severe adverse events have been reported [2-7]. A few can cause hepatic injury when given in high concentrations, and some even when used in recommended doses. Patients treated with CMD can be at risk when treated with certain, potentially harmful products (e.g. ephedra). Also pharmacological as well as toxicological interactions with Western medical interventions are sources of potential complications [8]. In a former study, several cases of temporary moderate liver enzyme elevations were observed $[9,10]$. It is still unclear to what extend this occurs in a clinical setting. For that reason and because of scientific interest and safety issues, the TCM hospital Bad Kötzting has developed a routinely applied complication screening (CSP) and quality control programme (QCP). CSP consists of a patient reporting outcome system for undesired effect and a standardised laboratory programme for detecting increased laboratory values of liver enzymes. All CMD delivered to the hospital are mainstreamed into the quality control programme. This safety proof aims mainly to exclude drugs which might contain e.g. toxic constituents, possess minor general quality or show contaminations.

\section{Aim}

To exemplify quality and safety measures for CMD administered at the TCM hospital Bad Kötzting. Results of preclinical quality proof of drugs, reported side effects and investigated liver enzyme elevations should be documented and discussed.

\section{Setting}

TCM hospital Bad Kötzting is equipped with 76 beds for inpatients; 8 Chinese physicians trained at the University of Chinese Medicine in Beijing (China) and one pharmacist collaborate with 6 German physicians. Patients can be referred to the hospital directly by their general practitioner. From the regular monitoring of the treatment process in the TCM hospital it is known that almost all patients in the hospital are usually treated with traditional Chinese drugs. This treatment usually goes along with acupuncture, Chinese manual and relaxation therapy. Drugs are given as raw materials in the form of decoctions and in rare cases as alcohol-based solutions. Number of prescriptions and of all single drugs as well as duration of treatment is documented systematically. Western therapies are continued or prescribed if necessary.

\section{Methods}

Preclinical Quality Control of TCM Medicinal Drugs

Before the TCM drugs can be routinely administered to the patients, all of them have to pass a comprehensive drug control program. To exclude possible falsifications and adulterations of herbal drugs, quantifiable HPLC-peaks and coloured TLC photographs were used for safety and botanical authenticity proof. Further investigations, such as chemical reaction, macro- and microscopy of the drugs, were performed. Special constituents were identified by HPLC, UV spectroscopy, titration and gravimetry according to the German pharmacopoeia Deutsches Arzneibuch (1996) and the pharmacopoeia of the People's Republic of China (English edition, 1992; 2005; 2010). This procedure was also applied to any herbal drug combination developed by mixing several individual drugs. In such cases, microscopy, TLC and/or HPLC analysis certificates were presented for individual drugs in order to confirm their authenticity. Therefore, 3-5 drugs from various regions of China were investigated for each species to avoid confusion. Most of the plant drugs were screened for microbial contamination (TAMC, TYMC, salmonella, Escherichia coli) aflatoxin (B1, B2, G1, G2) pesticides residues and heavy metals $(\mathrm{Pb}, \mathrm{Cd}, \mathrm{Hg}, \mathrm{As})$. The corresponding necessary tests required special laboratories in which they were performed prior to all other quality investigations. For the European Herbal Drug Regulatory Authority, the following limits for heavy metals are mandatory: lead $5 \mathrm{mg} / \mathrm{kg}$, cadmium $0.9 \mathrm{mg} / \mathrm{kg}$, mercury $0.2 \mathrm{mg} / \mathrm{kg}$, arsenic $2.0 \mathrm{mg} / \mathrm{kg}$. These standards are not mandatory for China. For all test certificates, the following basis was set: for microbiology Ph. Eur 2.6.31; for heavy metal contaminants recommendation Ph. Eur 01/2012; for the requirements of pesticides Ph. Eur 6.1, 2.8.13 and for aflatoxin the aflatoxins ban-V. In relation to TCM drugs without testing requirements for DC-HPLC fingerprint analysis of identity, ad hoc tests took place at the Center for Drug Research of the Ludwig-Maximilians University Munich.

\section{Complication Screening Programme}

As part of the routine quality assurance programme, all patients were asked to fill out a web-based questionnaire at admission to the hospital, at discharge and 6 months after discharge, anonymously. The entries were supported by an online health portal, named VITERIO (Virtual Tool for Education, Reporting, Information and Outcome).

An ethical review board was not involved because of the strictly routine character of the outcome study as part of a quality assurance programme. All legal obligations for the protection of personal data were met, and patients gave written informed consent when entering VITERIO.

At discharge, patients were asked to provide information on perceived side effects, i.e. to describe these complaints, symptoms and findings within the electronic documentation system. Furthermore, participants were asked what might have caused their complaints: TCM decoctions, acupuncture, tuina or others.

All inpatients discharged between September 1, 2012, to December 31, 2013 who had been treated with traditional Chinese drugs received routine blood sampling at admission (or not later than one day after admission) and in the last 3 days before discharge. We investigated the frequency of clinically relevant elevated liver enzymes in all consecutive patients treated at the hospital. The enzymes assessed routinely were aspartate aminotransferase (AST) and alanine aminotransferase (ALT). An elevated liver enzyme was defined as any elevation beyond the normal range in patients with normal values at admission, or any elevation beyond admission values in patients with elevated values at admission. Clinically relevant elevations were categorised as multiples of the upper normal limit (N) in 'up to 2-fold', and 'more than 2-fold' (beyond maximum normal value or elevated admission values). Liver injury was assumed as increased ALT activities of at least $2 \mathrm{~N}$, with $\mathrm{N}$ as the upper limit of normal $[3,11]$. The files of patients with more than 2-fold elevation of ALT were further scrutinised. Diagnosis, treatment (Western and all TCM drugs), duration of treatment, indica- 
Table 1. Reason for rejection: Investigations on microbial contamination, heavy metal load and pesticides; number of rejected samples: 5 ; total number of investigated samples: 23

\begin{tabular}{|c|c|c|c|c|c|c|c|c|}
\hline Name of drug & Identity & Quality & Concentration & Purity & $\begin{array}{l}\text { Heavy metal } \\
\text { load }\end{array}$ & Pesticides & Microbiology & Mycotoxcine \\
\hline $\begin{array}{c}\text { Aurantii immaturus } \\
\text { fructus (Zhishi) }\end{array}$ & $\varnothing$ & $\varnothing$ & $\varnothing$ & $\varnothing$ & $\varnothing$ & $\varnothing$ & $\begin{array}{l}\text { TAMC } 4 \times 10^{8} \\
\mathrm{KBE} / \mathrm{g}\end{array}$ & $\varnothing$ \\
\hline $\begin{array}{l}2 \times \text { Citri reticulatae } \\
\text { pericarpium (Chenpi) }\end{array}$ & $\varnothing$ & $\varnothing$ & $\varnothing$ & $\varnothing$ & $\varnothing$ & $\begin{array}{l}\text { dicofol: } \\
1.6 \mathrm{mg} / \mathrm{kg} \\
\text { dicofol: } \\
3.6 \mathrm{mg} / \mathrm{kg}\end{array}$ & $\varnothing$ & $\varnothing$ \\
\hline $\begin{array}{l}\text { Lonicerae flos } \\
\text { (Jin Yinhua) }\end{array}$ & $\varnothing$ & $\varnothing$ & $\varnothing$ & $\varnothing$ & $\begin{array}{l}\text { lead }(\mathrm{Pb}) \\
5.1 \mathrm{mg} / \mathrm{kg}\end{array}$ & $\begin{array}{l}\text { fenpro- } \\
\text { pathrin: } \\
0.05 \mathrm{mg} / \mathrm{kg}\end{array}$ & $\varnothing$ & $\varnothing$ \\
\hline $\begin{array}{l}\text { Bupleuri radix } \\
\text { (Chaihu) }\end{array}$ & $\varnothing$ & $\varnothing$ & $\varnothing$ & $\varnothing$ & $\varnothing$ & $\varnothing$ & $\begin{array}{l}\text { TAMC } 5 \times 10^{8} \\
\text { KBE/g; escherichia } \\
\text { coli }>3 \times 10^{3} \\
\mathrm{KBE} / \mathrm{g}\end{array}$ & $\varnothing$ \\
\hline
\end{tabular}

Standard values: lead $\leq 5.0 \mathrm{mg} / \mathrm{kg}$; dicofol $\leq$ 0.5; fenpropathrin $\leq 0.03$; TAMC $\leq 5 \mathrm{x} 107 \mathrm{KBE} / \mathrm{g}$; TYMC $\leq 5 \times 105 \mathrm{KBE} / \mathrm{g}$; escherichia coli $\leq 103$.

$\varnothing=$ normal finding.

tions of previous liver damage and follow-up data were extracted using a standard form, adjusted to the liver-specific Council for International Organisation of Medical Sciences (CIOMS) scale. Case data were used for causality assessment by two independent physicians (D.M., S.H.) and categorised according to the items of the CIOMS scale. Final score of CIOMS may range from -9 to +14 points; resulting causality levels are defined as follows: $\leq 0$ points = excluded; $1-2=$ unlikely; $3-5=$ possible; $6-8=$ probable; $\geq 9=$ highly probable $[3,11]$.

\section{Results}

\section{Quality Control Program}

From September 1, 2012 until end of 2013, all 23 samples of drugs delivered to the hospital were documented and tested. In 5 samples $(21.7 \%)$ the initial testing showed microbial contamination $(n=2)$, pesticides $(n=2)$ and heavy metals $(n=1)$; besides, no falsifications and adulterations could be found. Dicofol $(1.6 \mathrm{mg} / \mathrm{kg}$ and $3.6 \mathrm{mg} / \mathrm{kg}$ respectively vs. upper limit of normal $\leq 0.5 \mathrm{mg} / \mathrm{kg}$ ) and fenpropathrin $(0.05 \mathrm{mg} / \mathrm{kg}$ vs upper limit of normal $\leq 0.03$ $\mathrm{mg} / \mathrm{kg}$ ) were the most frequent pesticides. Further, contents of lead $(\mathrm{Pb})$ in lonicerae flos were slightly increased, and microbial enumeration tests (TAMC, total aerobic microbial count; TYMC, total yeast/ mold count) showed elevated levels of colony count. All contaminated drugs were excluded from the routine administration. Table 1 shows the results of all investigations.

\section{Complication Screening Program}

We surveyed 994 consecutive patients treated with TCM drugs at the hospital. Seventy-three percent of patients were female, the mean (SD) age was 53.5 (12.8) years, most of them experienced psychosomatic diseases, and the mean (SD) hospital stay was 26.2 (5.2) days. Additional diagnoses were e.g. back pain, hypertension and sleep disturbances (table 2).

$448(45.1 \%)$ of all patients reported at least one side effect of the treatment. 16 answers were invalid; 432 (43.5\%) patients were included into the analysis (table 3 ). They experienced mainly gastro-
Table 2. Patient characteristics of the study sample $(\mathrm{n}=994)$

\begin{tabular}{ll}
\hline Patient characteristics & \\
\hline Gender & 72.6 \\
$\quad$ Female, \% & $52.6 \pm 12.4$ \\
Age in years, mean \pm sd & 13.5 \\
$\quad$ Less than 41 years old, \% & 58.3 \\
41-60 years old, \% & 28.2 \\
More than 60 years old, \% & \\
Principal diagnoses (ICD 10) & 29.9 \\
F54 psychological factors of different classified diseases, $\%$ & 20.9 \\
F45 somatoform disorder, \% & 14.2 \\
F33 recurrent depression, \% & 11.8 \\
F32 episode of depression, \% & 5.8 \\
F43 maladaptation \% & \\
Additional diagnoses (ICD 10) & 36.0 \\
M54 back pain, \% & 20.4 \\
I10 hypertension, \% & 17.7 \\
F45 somatoform disorder, \% & 16.3 \\
M79 chronic pain disorder in soft tissue, \% & 12.9 \\
G47 sleep disturbances, \% & $26.2 \pm 5.2$ \\
Days spent in the hospital, mean \pm sd & \\
\hline
\end{tabular}

intestinal symptoms 135 (13.6\%), neurovegetative symptoms 107 (10.8\%), temporary deteriorations of pain $88(8.8 \%)$, diarrhoea 59 (5.9\%), nausea $16(1.6 \%)$ and vomiting $5(0.5 \%) .186$ (18.7\%) patients showed a various range of other symptoms. All participants were asked to attribute these side effects to certain interventions like decoctions of TCM drugs, acupuncture, tuina, qigong and others. The majority of 257 (59.4\%) from 432 reporting patients and 38.6\% of all patients respectively presumed a causative relation between side effects and decoctions (table 3). Diarrhoea, gastrointestinal and neurovegetative symptoms were the most commonly mentioned disorders in this perspective (table 3). Gastrointestinal symptoms appeared primarily as meteorism (flatulence) and abdominal pain. TCM decoctions were administered with 4 up to 5 prescriptions of individual herbs with a mean number of about 11 drugs (minimum 
Table 3. Reported side effects of 432 patients between January 9, 2012 and December 31, $2013(\mathrm{~N}=994)$; multiple responses possible

\begin{tabular}{|c|c|c|c|c|c|c|c|c|}
\hline Patients, n, \% & $\begin{array}{l}\text { Diarrhoea, } \\
59(5.9)\end{array}$ & $\begin{array}{l}\text { Nausea, } \\
16(1.6)\end{array}$ & $\begin{array}{l}\text { Vomiting, } \\
5(0.5)\end{array}$ & $\begin{array}{l}\text { Other } \\
\text { gastrointestinal } \\
\text { symptoms, } \\
135(13.6)\end{array}$ & $\begin{array}{l}\text { Neurovegetative } \\
\text { symptoms, } \\
107 \text { (10.8) }\end{array}$ & $\begin{array}{l}\text { Detoriation } \\
\text { of pain, } \\
88(8.8)\end{array}$ & $\begin{array}{l}\text { Others, } \\
186(18.7)\end{array}$ & $\begin{array}{l}\text { Total, } \\
432(43.5)\end{array}$ \\
\hline Decoction & 46 & 11 & 4 & 103 & 61 & 36 & 104 & 257 \\
\hline Acupuncture & 0 & 0 & 0 & 2 & & 12 & 7 & 25 \\
\hline Tuina & 0 & 0 & 0 & 0 & 5 & 8 & 9 & 18 \\
\hline Qigong & 1 & 0 & 0 & 1 & 0 & 2 & 3 & 7 \\
\hline Others & 12 & 5 & 1 & 29 & 33 & 30 & 63 & 125 \\
\hline
\end{tabular}

Table 4. Number of patients (n) with normal values and multiples of the upper normal limit $(\mathrm{N})$ at discharge with respect to alanine aminotransferase (ALT) and aspartate aminotransferase (AST); total patients $=994$

\begin{tabular}{llllll}
\hline Admission & Discharge & & & \\
\hline Within normal ${ }^{*}$ range & normal & $\mathrm{N}>1<2$ & $\mathrm{~N}>2$ & $\mathrm{~N}>6$ & $\mathrm{~N}>10$ \\
ALT, $\mathrm{n}=948$ & 891 & 53 & 2 & 1 & 1 \\
AST, $\mathrm{n}=966$ & 959 & 5 & 2 & 0 & 0 \\
Above normal ${ }^{*}$ range & & $\mathrm{N}>1<2$ & $\mathrm{~N}>2$ & $\mathrm{~N}>3$ & \\
ALT, $\mathrm{n}=46$ & 44 & 1 & 1 & \\
AST, $\mathrm{n}=28$ & & 3 & 0 & \\
\hline
\end{tabular}

*Norm limits of AST and ALT: $35 \mathrm{U} / 1$ (female); $50 \mathrm{U} / \mathrm{l}$ (male).
6 to maximum 19 components) during the hospital stay. Dose rate for each component was 6-10 g. Total dose rate per day and prescription was about $95 \mathrm{~g}$ served in two decoctions a day.

Further, we investigated the frequency of clinically relevant elevated liver enzymes in all survey participants. Table 4 shows the number of patients at discharge with normal values and multiples of the upper normal limit $\mathrm{N}>1<2, \mathrm{~N}>2, \mathrm{~N}>6$ and $\mathrm{N}>10$ of ALT and AST. 935 patients had normal values of liver enzymes at admission to the hospital. In 53 cases, laboratory results showed elevated ALT values in the category of $\mathrm{N}>1<2$ of the upper normal limit. Two patients showed multiples of both $\mathrm{N}>2$ and $\mathrm{N}>6$ in ALT. In comparison, AST values were elevated only 2 -fold in only two patients. One patient showed a more than 10-fold higher expression of ALT (table 4).

Table 4 also shows the number of patients (n) at discharge with multiples of the increased value at admission (N) of ALT and AST. ALT and AST values measured in 46 and 28 patients, respectively, whose values were increased at admission, showed a slight elevation $(\mathrm{N}>1<2)$ in 44 and 25 cases, respectively. In the categories $\mathrm{N}$ $>2$ and $\mathrm{N}>3$ only one patient each with increased ALT values was detected. In contrast, 3 patients each were detected with increased AST values (table 5). In 4 cases elevated ALT values improved slightly, but did not return to normal levels.

Details of the 6 patients with a more than 2-fold elevation (compared to maximum normal value or elevated admission values) of ALT are shown in table 5. Five female patients with different psychosomatic disorders (ICD-9: F31-F54) and one male patient with colitis ulcerosa (ICD-9 K51.9) were affected by hepatotoxicity. Two of these patients showed increased liver enzymes at admission (patients 5 and 6). All 6 patients were treated with decoctions twice a day and 15-26 drugs with dose rates between $30 \mathrm{~g}$ and $102 \mathrm{~g}$ per day. In addition to TCM drugs, they all received conventional drug treatment that was initiated prior to admission. Most of the conventional drugs (not in patient 2) have been associated with hepatotoxicity (celecoxib, mesalazin, pantoprazol, tocilizumab, zolpidem). Patient 1 and 3 suffered from gastrointestinal symptoms, such as diarrhoea, meteorism and abdominal pain during the hospital stay. In all patients, other causes of acute liver injury were excluded on a clinical level. Only patient 5 showed a history of hepatitis B. Control check-ups within the first 8 weeks after discharge and cessation of TCM drugs were denied by two patients (patient 4 and 6). In patient 1 and 3 ALT values returned to normal; patient 2 and 5 still had slight enhanced levels, but showed $>50 \%$ decrease between ALT peak and N. CMD treatment was continued only in patient 5, after liver enzyme values returned to normal. A causal relationship between ALT elevation and TCM drug therapy was assessed with CIOMS scale. Total scores of CIOMS scale ranged from 0 to 3 points with a resulting causality rated as 'possible' for patient 2; as 'unlikely' for patients 3-6; and as 'excluded' for patient 1.

To identify drugs which may be associated with an increased risk of ALT elevations, the frequencies of prescribed drugs in patients with elevated ALT values and in the 6 cases with more than 2 -fold elevated values respectively were compared with the prescription pattern of all patients without elevated liver enzymes (table 6). Data of drug prescriptions were available from 876 patients 739 of which had normal ALT levels, 137 elevated values and 6 more than 2 -fold elevated values, respectively. Additionally, in 383 patients self-reported side effects and frequency of prescribed drugs were matched with results from the other groups. Table 6 demonstrates the most frequently prescribed herbs: Achyranthis bidentatae radix (63.5\%), Paeoniae rubra radix (51.3\%), Bupleuri radix (51.1\%), Astragali radix (49.0\%), Aurantii immaturus fructus (44.5\%), Scutellariae radix (43.6\%) and Dipsaci radix (41.1\%). No noticeable differences regarding the frequency of prescribed drugs 


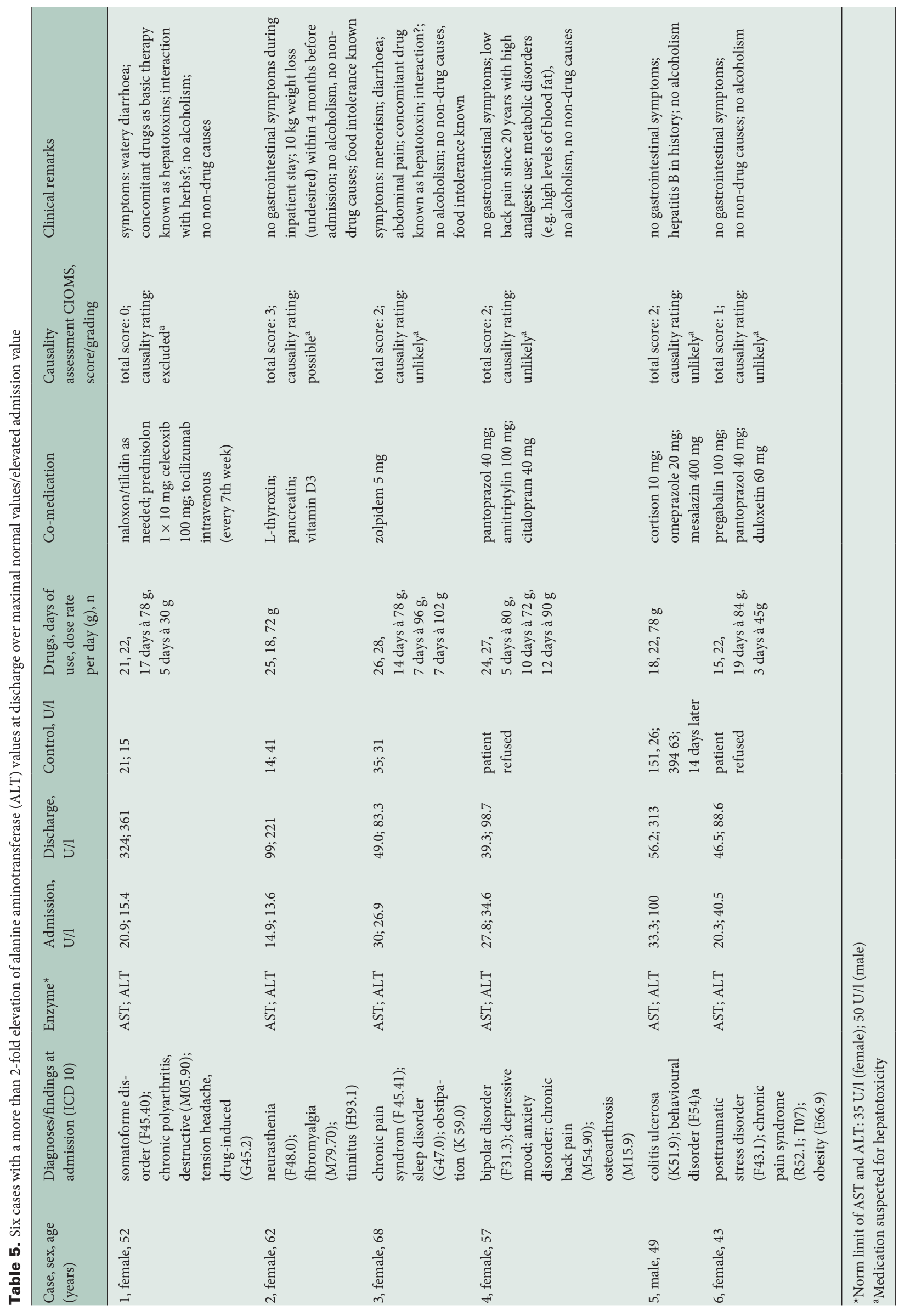


Table 6. Most frequently prescribed drugs in all 739 patients with normal values vs. 137 patients with elevated values of liver enzymes vs 383 patients with side effects

\begin{tabular}{|c|c|c|c|c|c|c|c|c|}
\hline \multirow[t]{2}{*}{ Name of drug } & \multicolumn{2}{|c|}{$\begin{array}{l}\text { Patients without } \\
\text { elevation, } \mathrm{n}=739\end{array}$} & \multicolumn{2}{|c|}{$\begin{array}{l}\text { Patients with } \\
\text { elevated liver } \\
\text { enzymes, } n=137\end{array}$} & \multicolumn{2}{|c|}{$\begin{array}{l}\text { Patients with } \\
\text { more than } 2 \text {-fold } \\
\text { elevation, } \mathrm{n}=6\end{array}$} & \multicolumn{2}{|c|}{$\begin{array}{l}\text { Patients with } \\
\text { subjective adverse } \\
\text { reactions, } \mathrm{n}=383\end{array}$} \\
\hline & $\mathrm{n}$ & $\%$ & $\mathrm{n}$ & $\%$ & $\mathrm{n}$ & $\%$ & $\mathrm{n}$ & $\%$ \\
\hline Achyranthis bidentatae radix & 476 & 64,4 & 80 & 61.1 & 5 & 83.3 & 242 & 63.2 \\
\hline Paeoniae rubra radix & 382 & 51,7 & 67 & 51.1 & 5 & 83.3 & 201 & 52.5 \\
\hline Bupleuri radix & 385 & 52,1 & 63 & 48.1 & 1 & 16.7 & 204 & 53.3 \\
\hline Astragali radix & 373 & 50,5 & 56 & 42.7 & 5 & 83.3 & 194 & 50.7 \\
\hline Aurantii immaturus fructus & 344 & 46,5 & 46 & 35.1 & 3 & 50.0 & 173 & 45.2 \\
\hline Scutellariae radix & 323 & 43,7 & 59 & 45.0 & 4 & 66.7 & 176 & 46.0 \\
\hline Dipsaci radix & 298 & 40,3 & 62 & 47.3 & 4 & 66.7 & 159 & 41.5 \\
\hline Ligustici chuanxiong rhizoma & 294 & 39,8 & 50 & 38.2 & 2 & 33.3 & 149 & 38.9 \\
\hline Loranthi ramulus & 278 & 37,6 & 58 & 44.3 & 3 & 50.0 & 147 & 38.4 \\
\hline Aurantii fructus & 284 & 38,4 & 33 & 25.2 & 1 & 16.7 & 142 & 37.1 \\
\hline Sparganii tuber (rhizoma) & 278 & 37,6 & 38 & 29.0 & 2 & 33.3 & 140 & 36.6 \\
\hline Bambusae caulis in taeniam & 258 & 34,9 & 49 & 37.4 & 2 & 33.3 & 146 & 38.1 \\
\hline Poria (Stücke) & 241 & 32,6 & 43 & 32.8 & 1 & 16.7 & 118 & 30.8 \\
\hline Curcumae longae rhizoma & 239 & 32,3 & 37 & 28.2 & 4 & 66.7 & 118 & 30.8 \\
\hline Ligustri lucidi fructus & 226 & 30,6 & 39 & 29.8 & 1 & 16.7 & 116 & 30.3 \\
\hline Coicis semen & 208 & 28,1 & 44 & 33.6 & 1 & 16.7 & 117 & 30.5 \\
\hline Atractylodis rhizoma & 215 & 29,1 & 36 & 27.5 & 3 & 50.0 & 111 & 29.0 \\
\hline Citri reticulatae pericarpium & 214 & 29,0 & 32 & 24.4 & 1 & 16.7 & 127 & 33.2 \\
\hline Magnoliae officinalis cortex & 185 & 25,0 & 34 & 26.0 & 1 & 16.7 & 111 & 29.0 \\
\hline Cinnamomi ramulus & 170 & 23,0 & 46 & 35.1 & 1 & 16.7 & 91 & 23.8 \\
\hline Notopterygii rhizoma seu radix & 172 & 23,3 & 40 & 30.5 & 0 & & 100 & 26.1 \\
\hline Angelicae pubescentis radix & 168 & 22,7 & 41 & 31.3 & 0 & & 99 & 25.8 \\
\hline Liquidambaris fructus & 173 & 23,4 & 27 & 20.6 & 2 & 33.3 & 81 & 21.1 \\
\hline Mori ramulus & 152 & 20,6 & 38 & 29.0 & 1 & 16.7 & 85 & 22.2 \\
\hline Curcumae radix & 151 & 20,4 & 18 & 13.7 & 2 & 33.3 & 76 & 19.8 \\
\hline Cuscutae semen & 143 & 19,4 & 22 & 16.8 & 0 & & 66 & 17.2 \\
\hline Paeoniae alba radix & 143 & 19,4 & 17 & 13.0 & 0 & & 67 & 17.5 \\
\hline Pinelliae praeparatae rhizoma & 134 & 18,1 & 18 & 13.7 & 2 & 33.3 & 66 & 17.2 \\
\hline Lycii fructus & 120 & 16,2 & 17 & 13.0 & 1 & 16.7 & 50 & 13.1 \\
\hline Tribuli fructus & 122 & 16,5 & 13 & 9.9 & 0 & & 62 & 16.2 \\
\hline Angelicae dahuricae radix & 120 & 16,2 & 12 & 9.2 & 0 & & 66 & 17.2 \\
\hline Angelicae sinensis radix & 108 & 14,6 & 17 & 13.0 & 0 & & 52 & 13.6 \\
\hline Corydalis rhizoma & 111 & 15,0 & 13 & 9.9 & 0 & & 56 & 14.6 \\
\hline Spatholobi caulis & 107 & 14,5 & 12 & 9.2 & 0 & & 68 & 17.8 \\
\hline Persicae semen & 100 & 13,5 & 17 & 13.0 & 0 & & 57 & 14.9 \\
\hline Lumbricus $(\mathrm{t})$ & 107 & 14,5 & 9 & 6.9 & 1 & 16.7 & 47 & 12.3 \\
\hline Polygalae radix & 103 & 13,9 & 12 & 9.3 & 0 & & 45 & 11.7 \\
\hline Albiziae cortex & 101 & 13,7 & 12 & 9.3 & 0 & & 46 & 12.0 \\
\hline Lycopodii herba & 99 & 13,4 & 14 & 10.7 & 0 & & 50 & 13.1 \\
\hline Carthami flos & 106 & 14,3 & 6 & 4.7 & 0 & & 51 & 13.1 \\
\hline Codonopsis pilosulae radix & 92 & 12,4 & 20 & 15.3 & 2 & 33.3 & 58 & 15.1 \\
\hline Epimedii herba & 94 & 12,7 & 14 & 10.7 & 1 & 16.7 & 55 & 14.4 \\
\hline Meliae toosendan fructus & 85 & 11,5 & 17 & 13.0 & 1 & 16.7 & 51 & 13.3 \\
\hline Ledebouriellae radix & 88 & 11,9 & 10 & 7.6 & 1 & 16.7 & 44 & 11.5 \\
\hline Phellodendri cortex & 83 & 11,2 & 6 & 4.6 & 0 & & 39 & 10.2 \\
\hline Lycopi herba & 79 & 10,7 & 6 & 4.6 & 0 & & 31 & 8.1 \\
\hline Prunella spica & 30 & 4,1 & 11 & 8.5 & 0 & & 16 & 4.2 \\
\hline Pyrrosiae folium & 6 & 8 & 4 & 3.1 & 0 & & 2 & 0.5 \\
\hline
\end{tabular}

between the groups were found. For Bupleuri radix a risk ratio (RR) of 0.19 (95\% confidence interval (CI): 0.01-1.66) for a more than 2-fold ALT elevation could be derived. TheRR rates for Astragali radix and Scutellariae radix were 5.21 (95\% CI: 0.60-119.75) and 2.59 (95\% CI: 0.41-20.24) respectively.

Finally, hepatotoxicity of the most important published TCM drugs was compared (table 7). In 4 and 3 of 6 patients with liver injury, ( $\mathrm{N}>2$ in ALT as the upper limit of normal) herbs with potential hepatotoxicity, i.e. Scutellariae radix (Huanquin) and Rhei radix et rhizome (Dahuang), and Cassiae semen (Juemingzi) and Meliae toosendan fructus (Chuanlianzi) respectively were applied. Prescriptions containing Scutellariae radix and Rhei radix et rhizome were administered to patient 2 and 6; patient 3 received all 4 suspicious drugs during hospital stay for more than 4 weeks. 
Table 7. TCM drugs showing potential hepatotoxicity; frequency of their use in TCM hospital; frequency in patients with elevated liver enzymes and patientreported adverse reactions, respectively

\begin{tabular}{|c|c|c|c|c|c|c|c|c|}
\hline \multirow[t]{2}{*}{$\begin{array}{l}\text { Reported hepatotoxicity of TCM drugs / } \\
\text { name of drug }\end{array}$} & \multicolumn{2}{|c|}{$\begin{array}{l}\text { Total patient } \\
\text { sample, } \mathrm{n}=876\end{array}$} & \multicolumn{2}{|c|}{$\begin{array}{l}\text { Patients with } \\
\text { elevated liver } \\
\text { enzymes, } \mathrm{n}=137\end{array}$} & \multicolumn{2}{|c|}{$\begin{array}{l}\text { Patients with } \\
\text { more than } 2 \text {-fold } \\
\text { elevation, } \mathrm{n}=6\end{array}$} & \multicolumn{2}{|c|}{$\begin{array}{l}\text { Patients with } \\
\text { subjective adverse } \\
\text { reactions, } \mathrm{n}=383\end{array}$} \\
\hline & $\mathrm{n}$ & $\%$ & $\mathrm{n}$ & $\%$ & $\mathrm{n}$ & $\%$ & $\mathrm{n}$ & $\%$ \\
\hline Agkistrodon (t)/Qishe & 0 & & 0 & & 0 & & 0 & \\
\hline Alismatis rhizoma/Zexie & 30 & 3.4 & 4 & 3.1 & 0 & & 10 & 2.6 \\
\hline Artemisia capillaris/yinchen hao & 0 & & 0 & & 0 & & 0 & \\
\hline Bombyx batryticatus (t)/Baijiangcan & 58 & 6.6 & 4 & 3.1 & 0 & & 25 & 6.5 \\
\hline Bupleurum/chaihu & 448 & 51.1 & 63 & 48.2 & 0 & & 201 & 53.3 \\
\hline Cassiae semen/Juemingzi (senna) & 40 & 4.6 & 3 & 2.3 & 1 & 16.7 & 16 & 4.2 \\
\hline Dictamni radicis cortex/Baixianpi & 22 & 2.5 & 2 & 1.6 & 0 & & 12 & 3.1 \\
\hline Ephedrae herba/Mahuang & 17 & 1.9 & 2 & 1.6 & 0 & & 6 & 1.6 \\
\hline Galla chinensis/Wubeizi & 3 & 0.3 & 0 & & 0 & & 1 & 0.3 \\
\hline Ginseng radix/Renshen & 1 & 0.1 & 1 & 0.8 & 0 & & 0 & \\
\hline Glycyrrhizae radix/gancao & 16 & 1.8 & 0 & & 0 & & 7 & 1.8 \\
\hline Meliae toosendan fructus/Chuanlianzi & 102 & 11.6 & 17 & 13.2 & 1 & 16.7 & 51 & 13.3 \\
\hline Menthae herba/Bohe & 58 & 6.6 & 7 & 5.3 & 0 & & 22 & 5.7 \\
\hline Oldenlandiae diffusa herba/Baihuasheca & 1 & 0.1 & 1 & 0.8 & 0 & & 0 & \\
\hline Polygoni cuspidati rhizoma/Huzhang & 0 & & 0 & & 0 & & 0 & \\
\hline Polygoni multiflora caulis/Shouwuteng & 31 & 3.5 & 1 & 0.8 & 0 & & 13 & 3.5 \\
\hline Polygoni multiflori radix/Heshouwu & 4 & 0.5 & 0 & & 0 & & 0 & \\
\hline Puerariae radix/Gegen & 35 & 4.0 & 8 & 6.2 & 0 & & 12 & 3.1 \\
\hline Punicae granati pericarpium/Shiliupi & 0 & & 0 & & 0 & & 0 & \\
\hline Psoraleae fructus/buguzhi & 33 & 3.8 & 8 & 6.2 & 0 & & 15 & 3.9 \\
\hline Rhei radix et rhizoma/Dahuang & 74 & 8.4 & 12 & 9.3 & 3 & 50.0 & 41 & 10.7 \\
\hline Rheum palmatum/Dahuang & 0 & & 0 & & 0 & & 0 & \\
\hline Scolopendra (t)/Wugong & 0 & & 0 & & 0 & & 0 & \\
\hline Scorpio Buthus martensii/Quanxie & 3 & 0.3 & 0 & & 0 & & 1 & 0.3 \\
\hline Scutellariae radix/Huangqin & 382 & 43.6 & 59 & 45.0 & 4 & 66.7 & 146 & 46.0 \\
\hline Trichosanthis radix/Tianhuafen & 1 & 0.1 & 11 & 8.5 & 0 & & 0 & \\
\hline Tripterygii wilfordii radix/Leigongteng & 0 & & 0 & & 0 & & 0 & \\
\hline Xanthii fructus/Cangerzi & 19 & 2.0 & 3 & 2.3 & 0 & & 5 & 1.3 \\
\hline
\end{tabular}

\section{Discussion}

Plants are natural producers of chemical substances, enabling treatment of human ailments since ancient times. Many of them are harmless or have only minor and transient adverse effects. Some herbal chemicals in medicinal plants of traditional and modern medicine, however, carry the risk of herb-induced liver injury (HILI) when given in high concentrations, and some even when used in recommended doses $[12,13]$. In many cases, the specific TCM drug that is responsible for the liver injury is unclear. In order to ensure the quality of the TCM drugs given to the patients at the TCM hospital Bad Kötzting, a comprehensive pretreatment drug control program as well as a complication screening program has been installed. Gastrointestinal symptoms, hepatotoxicity and interactions causing elevated or decreased drug levels of mainstream medical drugs are some of the safety information that should be given by administering TCM drugs to admitted patients. Since herbal medicines contain more than one pharmacologically active ingredient and are commonly used in combination with other prescribed herbal and conventional drugs, there is a risk of potential herb-drug interactions which might lead to serious clinical consequences [14]. Concurrent administration of herbal and conventional medicines was found in the majority of patients and was maintained in the course of their hospital stay, if necessary. Despite safety concerns, Chinese medicine appears to be relatively safe with comparatively few reports of adverse reactions compared with overall drug reports. A recent prospective population-based study from Iceland [15] found an annual incidence rate of druginduced liver injury (DILI) of approximately 19 cases per 100,000 habitants per year. The most commonly implicated drugs in this general population were amoxicillin-clavulanate $(22 \%)$, diclofenac (6\%), azathioprine (4\%), infliximab (4\%), and nitrofurantoin (4\%). The median duration of therapy was 20 days (range, 8-77 days). The use of some herbal TCM products carries the rare risk of liver injury $[11,16]$. At present, the English literature refers to about 40 single TCM herbs with potential hepatotoxicity $[3,11]$. A recent review of Teschke et.al [3] gives a good overview of potentially harmful TCM drugs also used for comparison in our survey. Nevertheless, a list of these drugs still has to be rated carefully. Especially drugs with a high prescription rate, such as Scutellariae radix (Huanquin) and Bupleuri radix (Chaihu), have a RR with an extremely broad CI (Scutellariae radix: 2.59 (95\% CI: 0.41-20.24); Bupleuri radix: 0.19 (95\%CI: 0.01-1.66).

Based on our data of 994 inpatients admitted to the hospital between September 1, 2012 and December 31, 2013, we assessed the patient-perceived occurrence of reported side effects. The adverse reaction reporting system revealed that $17.6 \%$ of all inpatients of the hospital reported gastrointestinal symptoms. $5.7 \%$ of these patients are afflicted by diarrhea, mostly induced by applied decoctions. The reporting system lacks precoded complication lists and thus must be 
completed by half-structured interviews. Liver injury was assessed based on ALT levels that were more than 2-fold above the upper limit of normal. 6 from 994 patients within the observational timespan fulfilled this definition. Patients were advised to cease all supplement use and were monitored for signs of significant liver dysfunction. Drug discontinuation and therapy reconciliation are the main measures in patient management to minimize occurrence of acute liver failure. To identify the nature and components of the liver injury, characterisation of the clinical phenotype or pattern of hepatic injury is helpful [10]. Differentiation between hepatocellular, cholestatic or mixed type hepatotoxicity is facilitated by comparing initial ALT and ALP values (ALP serum activities) $[3,11]$. Unfortunately, the management of the complication screening program did not yet provide serum level of ALP routinely - a must for the future.

Although side effects decreased in all patients and liver enzyme levels normalised after discontinuing TCM drugs, the hospital is committed to inform patients according to the Summary of Product Characteristics (SPC) guideline. Liver injury occurs in $\geq 1 / 1,000$ to $\leq 1 / 100$ cases (uncommon adverse reaction); symptoms of diarrhea occur in $\geq 1 / 100$ to $<1 / 10$ cases (common adverse event).

Risks should be identified and communicated to the academic and medical public. As in conventional pharmaceuticals, the confidence with which a TCM diagnosis of liver injury is made depends to a great extent on the number of previously reported and published cases [17]. Nevertheless, scientific strategy has to keep an eye on a fair benefit-risk ratio in order to balance both impact factors of medical care. Therefore, more financial support from political and research funding authorities is needed to realise a better framework for clinical research.

We assessed the occurrence rate and causality levels according to the criteria of CIOMS (Council for International Organizations of Medical Sciences) scale which is a suitable instrument for causality assessment within clinical routine. Surprisingly, all patients involved in the study showed only a few points on the CIOMS scale. A systematic data collection assessing continued drug therapy after normalisation of the liver enzymes is still pending and a further challenge for the complication screening programme.

The results comparing the frequency and quality of drug prescriptions in the different groups of the survey have to be interpreted with great caution. There is no simple correlation between the number of cases in which a single drug has been prescribed and an increased risk of adverse events or liver toxicity. An exception could be shown in the analysis of different frequencies of drug prescriptions in the groups 'all patients' and 'patients with liver injury'.

The aim of the quality control program of TCM drugs is to avoid adulteration and contamination of herbal medicinal products. A few years back, the results of the examinations revealed more problems associated with drug contents than with contamination [18]. Nowadays, troubles with contamination are more prominent. The spectrum of contaminations contains dust, fungi, insects, microbes, rodents, parasites, pesticides, toxic heavy metals and/or mainstream drugs [18]. Present examinations of our survey show that heavy metals and pesticides are the most striking contaminants. All mistaken and contaminated drugs were rejected from the routine administration.

\section{Conclusion}

Further research on safety of and compliance with traditional Chinese drug treatment is clearly warranted in order to find and teach strategies by which these problems can be anticipated, prevented, or managed.

\section{Disclosure Statement}

The authors declare that there is no conflict of interests concerning this paper.

\section{References}

1 Eardley S, Bishop FL, Prescott P, et al.: A systematic literature review of complementary and alternative medicine prevalence in EU. Forsch Komplementmed 2012; 19(suppl 2):18-28.

2 Rossi S, Navarro VJ: Herbs and liver injury: a clinical perspective. Clin Gastroenterol Hepatol 2014;12:10691076.

3 Teschke R, Zhang L, Long H, Schwarzenboeck A, Schmidt-Taenzer W, Genthner A, Wolff A, Frenzel C Schulze J, Eickhoff A: Traditional Chinese Medicine and herbal hepatotoxicity: a tabular compilation of reported cases. Ann Hepatol 2015;14:7-19.

4 Woo HJ, Kim HY, Choi ES, Cho YH, Kim Y, Lee JH, Jang E: Drug-induced liver injury: A 2-year retrospective study of 1,169 hospitalized patients in a single medical center. Phytomedicine 2015;22;:1201-1205.

5 Dağ MS, Aydınlı M, Oztürk ZA, Türkbeyler IH, Koruk I, Savaş MC, Koruk M, Kadayıfçı A: Drug- and herbinduced liver injury: a case series from a single center. Turk J Gastroenterol 2014;25:41-45.

6 Zhao P, Wang C, Liu W, Wang F: Acute liver failure associated with traditional Chinese medicine: report of 30 cases from seven tertiary hospitals in China. Crit Care Med 2014;42:e296-299.
7 Björnsson ES: Drug-induced liver injury: an overview over the most critical compounds. Arch Toxicol 2015; 89:327-334.

8 Izzo AA, Ernst E: Interactions between herbal medicines and prescribed drugs: an updated systematic review. Drugs 2009;69:1777-1798.

9 Melchart D, Linde K, Hager S, Kaesmar J, Shaw D, Bauer R, Weidenhammer W: Monitoring of liver enzymes in patients treated with traditional Chinese drugs. Complement Ther Med 1999;7:208-216.

10 Melchart D, Weidenhammer W, Hager S, Shaw D, Bauer R: Liver enzyme elevations in patients treated with traditional Chinese medicine. JAMA 1999;282:28-29.

11 Teschke R, Wolff A, Frenzel C, Schwarzenboeck A, Schulze J, Eickhoff A: Drug and herb induced liver injury: Council for International Organizations of Medical Sciences scale for causality assessment. World J Hepatol 2014;27:17-32.

12 Abdualmjid RJ, Sergi C: Hepatotoxic botanicals - an evidence-based systematic review. J Pharm Pharmaceut Sci 2013;16:376-404.

13 Buchornatavakul C, Reddy KR: Review article: herbal and dietary supplement hepatotoxicity. Aliment Pharmacol Ther 2013;37:3-17.
14 Fasinu PS, Bouic PJ, Rosenkranz B: An overview of the evidence and mechanisms of herb-drug interactions. Front Pharmacol 2012;30:69.

15 Björnsson ES, Bergmann OM, Björnsson HK, Kvaran $\mathrm{RB}$, Olafsson S: Incidence, presentation, and outcomes in patients with drug-induced liver injury in the genera population of Iceland. Gastroenterology 2013;144: 1419-1425.

16 LiverTox. Clinical and research information on druginduced liver injury. herbals and dietary supplements. www.livertox.nih.gov/Herbals_and_Dietary_Supplements.htm (accessed February 26, 2016).

17 Melchart D, Hager S, Weidenhammer W, Liao JZ, Söllner C, Linde K: Tolerance of and compliance with traditional drug therapy among patients in a hospital for Chinese medicine in Germany. Int J Risk Safety Med 1998;11:61-64

18 Posadzki P, Watson L, Ernst E: Contamination and adulteration of herbal medicinal products (HMPs): an overview of systematic reviews. Eur J Clin Pharmacol 2013;69:295-307. 